\title{
A trip project for more demanding clientele involving the climb on Matterhorn
}

\author{
Vratislav KOZÁK \\ Tomas Bata University in Zlin, Zlin, Czech Republic \\ kozak@utb.cz \\ Vendula KOLÁŘOVÁ \\ Tomas Bata University in Zlin, Zlin, Czech Republic \\ vkolarova@utb.cz
}

\begin{abstract}
Tourism is one of the areas which is constantly making progress. While 10 years ago tourists enjoyed a holiday by the sea in a beautiful resort with even more beautiful weather and clean beach, eventually winter holiday in the ski resort with regularly adjusted slope, enough snow and comfortable accommodation, today it is different. Based on a survey among the clients of the Slovak travel agency it was found out that the clients are interested in the trip involving the climb on the Matterhorn mountain which has not been offered in the proposition yet. Travel agency together with the specialized academic workplace processed the trip project for more demanding clientele to this less common destination, this means on Matterhorn mountain, accompanied by the mountain guides. This way the travel agency gained a competitive advantage because no other Slovak travel agency organizes a tour of this type. It has to be considered the safety of the participants of the trip and wind conditions in the final destination. The profit margin was established at 45\%. Under the term "demanding clientele" we mean the clients who do not long for a stay at the seaside but on the contrary they love to increase adrenaline and are not afraid to test their abilities in extreme situations. There is a competition not only among the individual travel agencies but due to access to information via the Internet there are more and more tourists who are able to arrange a demanding sightseeing trip to various countries themselves. The special exception is mountain tourism and climbing which is demanding for the accompanying services - providing mounting guides, transport of the backpacks in hilly terrain. Climbing is the risky sport, it is necessary to have a secure professional accompaniment.
\end{abstract}

Keywords: travel agency, trip project for more demanding clientele, climbing, Matterhorn mountain.

\section{Introduction}

It is possible to define tourism as a movement of people on the places for various purposes which are found out of their surroundings and which are far-away from their home environment. But the migration and the normal daily work does not belong to this category. (Jakubíková, 2009, s. 18) The heart of the matter of tourism is a tourist and his experience during travel and stay in the destination. To be able to offer satisfaction and good service to the tourist, the service provider has to understand the tourist's wish as well the factors which can influence the choice of the destination, the way of travelling and the final choice among numerous activities which are offered in various destinations of the trip. But it is possible only in the case when the providers follow the tourists to the highest possible extent and this way they can approach to the development and bigger attractiveness of their equipment, differ from their competitors and by this attract more clients. (Goeldner a Ritchie, 2009, s. 13-14) Increased competition among the travel agencies becomes evident by increased demands on the employees. Dai, Y.-D., Zhuang, W.-L., Huan, T.-C. (2019) tried to indicate the 
impact of the resistance of the travel agency employees on their intention to leave work and simultaneously they examined whether abusive supervision mitigates the effects above. The results indicate that the travel agency emploees' resistance can reduce their intention to leave their work and increase their workload. Also abusing supervision has a moderating effect on the disputes in the workplace and creates better well-being among the employees.

On the importance of the quality and positive reviews for users the research of Liu, X., Zhang, Z., Law, R., Zhang, Z. (2019) was focused. Many online travel agencies (OTA) offer online incentives to promote high quality and if possible also positive reviews. The effects of these incentive programs on the influence of acquiring the new clients remain unclear. The analyzes show the following: (1) the users with more public reviews tend to make more effort to publish more reviews, (2) increasing number of posted positive reviews for the hotel will cause subsequent visitors to make effort to write their own review, (3) the effect of a limited number of negative reviews is decreasing, (4) highly qualified reviewers tend to make more effort on reviews when they are in strong competition from other reviewers.

The team of authors Chou, C.Y., Huang, C.H., Lin, T.-A. (2018) focused on the research of innovative behavior of the employees. They state that the innovative behavior of the employees of frontline service is "the moment of truth" which significantly affects the organizational performance. This study used SPSS 24.0 and AMOS 20.0 for examination of the structural model and hypothetical effects (1) of various dimensions of the intellectual capital of the organization on innovative behavior of the head service staff and (2) the common consumer value creation by using innovative behavior of the head service staff across the dimension of the organizational intellectual capital. It was found out that the human capital and customer capital positively affects the innovative behavior of the frontline service workers. Interaction between the common creation of the consumer value, human and customer capital had the significant strengthening effect on the innovative behavior of the frontline service workers.

\section{Literature review}

Alpine tourism has many specifics that many researchers are focusing on. For instance Cerqueira Rebelo, Catia Filipa; Gomes Ezequiel, Graca Maria; da Custodia Machado Mendes. Susana Luisa; (2018) concluded that the alpine adventure tourism represents 20\% of current tourism revenue and there is a realistic assumption of the further growth. Based on that there is a strong need for better understanding and dedication to this segment. Pico Mountain, the mountain destination in Portugal, followed this growth trend but the lack of knowledge about the alpine adventure tourism is persisting. That's why the goal is to define the profile of the visitor on Pico Mountain and also to assess the importance of the role of the mountain guides when climbing up to the Pico Mountain. To achieve this goal quantitative analysis based on a survey applied on the territory was used. The results indicated that the visitors of Pico Mountain are mostly young, European, inexperienced and „packers“ adventurous tourists who are interested in the „soft" adventurous activities. Mountain guides played an important role in the mountain climbing for $90 \%$ of the respondents, the same as the possibility to influence their choice. And what more, the sense of security guaranteed by the guide is the most significant characteristic of the mountain guides for all respondents and is the main reason why they are hired.

Esfahani, Mahdi; Musa, Ghazali; Khoo, Selina (2017) surveyed how psychological and physical conditions can influence the behavior and satisfaction of the mountain 
climbers.This exploratory study aimed to examine the influence of spirituality and the level of physical activity on responsible behavior and satisfaction with the climbing activity among the climbers on the mountain Kinabalu in Borneo. The findings showed that the spirituality affects positively both the responsible climbing behavior and also satisfaction. High level of physical activity brings together both of these relationships. The study contributes to understanding important roles and level of physical activity in influencing responsible behavior and satisfaction of climbers.

Apollo, Michal (2017) notes in his study that hiking and mountaineering are expanding more and more every year.Among the key factors which determine the travel destination in the recent years is the the level of availability for the tourists. To improve the current level of availability of the tourism it is necessary to know all factors which can influence the client access. Access to climbing sites is more complicated than to simple tourist destinations which only require the transport availability and services on the place. The real availability for mountaineering consists of two factors: (1) place accessibility (transport system and services on the place) and (2) real assess which includes such factors as social, economic, climatic and psychophysical environment the same as the presence of the climbing activity that can have the positive or negative impact on the opportunity to engage in the use of the offered activities. It means that the conditions must be such as to enable to make the real contact with the tourist offer. The examples of current availability conditions in the Himalayas serve to illustrate all the parts of the conceptual framework. More comprehensive understanding of different aspects of mountaineering availability offers an important view of the tourists who are planning climbing activities and of the local climbing communities that develop infrastructure and services.

The research goal of (Caber, Meltem; Albayrak, Tahir, 2016) was to explain the motivation of tourist climbers with help of push and pull framework and explore the relationship between the motivation of the tourists and total satisfaction.in the survey of 473 tourists-climbers in the region Geyikbaym in Turkey for the most important motives "the physical environment" and "the challenge" were determined while as "the most important search" and "mountaineering tourist infrastructure" as the most important factor the motivation was determined. The conclusions of this study next suggested that total satisfaction of the climbers can be determined by the motivation. The results also showed that the motivation of the climbers can differ according to their experience.

Despite its importance as an alternative species of tourism the mountaineering is generally considered to be the sport activity and has been studied by academics with a focus on sport management and health injuries (Albayrak, Tahir; Caber, Meltem, 2016). This study emphasizes the growing popularity of mountaineering in the sector of tourism and tries to examine the perception of quality of the rock climbers of different attributes of the goals and the influence of every perception on the total satisfaction using asymmetric impact and performance analysis. The results showed that the infrastructure and accommodation are significant factors but with little importance in the eyes of tourists who took part in the mountain climb in the area Geyikbayiri. These factors were the most important determinants of the total satisfaction of the first visitors although they were not the basic needs of the visitors returning again.

The study Mu, Yang; Nepal, Sanjay (2016) examines the perception of the risk and death of the trekkers connected with the alpine adventure tourism based on their real experience during the trek to the base camp Everest. The study is based on the field work of 
the authors done during the period from April to May 2014. The questions of the interview were focused on the perception of trekkers' risks connected with their own activities and risks that arise with professional mountaineers and the guides Sherpa. The results show that the mountaineers realized the differences in risks associated with climbing and trekking and made risk ranking which the mountaineers are willing to accept. But when other or higher risk appeared during the trek, the climb became fear and emotional suffering. The study ends with a proposal that more research is needed to explore the dynamic emotional state of the tourists searching for the adventure, classification of alpine adventures and understanding of the tourists searching for the adventure by local population.

The association of leisure time studies Chattanooga in Australia and New Zealand is the central point of many climbing sites on the rocks which are good for the local economy. The lack of metrics that quantify the positive impacts provides reliable access to the land and protection for problematics of climbing. The influx of climbers complicates the policy and landscape management priority. The aim of the study Bailey, A.W., Hungenberg, E. (2018) was to identify the economic impacts of climbing in Chattanooga and to clarify the managerial preferences of the activity participants. The surveys were conducted over a period of nine months in five popular mountaineering areas. The information dealing with demographics, style and level of climbing, management preferences and expenditure patterns were collected. The economic data were analyzed with help of IMPLAN software to identify the indirect and consequential impacts and also on the impact on the state and federal taxes. The total contribution of 7 million dollars was evaluated whereas other half amounts were state and federal taxes. Control choice varied according to the climbing place and the number of visitors that demonstrated the diversity of views in the climbing community.

In the area of protection of protected territory the interested parties are ranging from supranational to local decision-making bodies. Although there has been the fundamental research on the parties involved, there is limited investigation as for their connection to development of experience in the area of tourism based on nature in heavily visited protected areas. Based on the stakeholders theory this article examines the possibilities of the stakeholders to develop the alternative experience of visitors on the iconic mountain, namely national park Wollumbin-Mount Warning National Park on the east of Australia. Due to the popularity of climbing on the mountainside Wollumbin a number of questions related to sustainable visitor management including overcrowding, environmental impact and sensitivity of native people as for climbing appeared. Based on the interpretative methodology semi-structured interviews with 22 key stakeholders of the group Wollumbin were done. The analysis of these interviews showed that during developing alternative experiences in the protected areas it is important to balance natural and cultural priorities, create suitable solution alternatives and overcome the challenges in the field of tourism. (Wilson, E., Nielsen, N., Scherrer, P., (...), Moyle, B., Weiler, B. 2018)

The platform UK Limited trading as the group Taylor and Francis started to organize the climbing in the Caribbean in the half of the 20th century. Unfortunately growing competition and a chance in the motivation of tourists forces the authorities that manage these regions to introduce a new tourism offer that is not directly based on 3S (sun, sand and sea) or $3 \mathrm{E}$ (entertainment, excitement, education). Tourism, hiking and climbing defined as adventurous climbing could be one of them. The article examines the potential for climbing in Cuba by verification of availability for tourists. Evaluation is based on a real availability framework which consists of two factors: (1) availability of the destination and (2) real 
approach. The results of the research show that climbing in Cuba should be considered for one of the key factors that contribute to the development, prosperity and well-being of all involved parties and mainly for the communities outside the enclaved of tourism. (Apollo, M., Rettinger, R. 2018)

Although they have recently explored the study of tourism (Vidon, E.S., Rickly, J.M. 2018), the recent work suggest that the theory of alienation as the dialectic of authenticity have a lot to contribute to our understanding of tourism motivation. This article examines the role of alienation in the tourist's motivation for tourism and climbing. These tourists namely describe only temporary and retrospective relief from anxiety expressing authenticity as an inscrutable experience lying on the horizon in the next adventure or in the memory as a past. Alienation is still a present component of the human condition and as such the anxiety in our lives is omnipresent and contributes significantly to the tourist desires for escape into nature, rejuvenation and existential experience.

From its last significant explosion in 1963 Mount Agung, the highest mountain in the province Bali in the district Selat, Karangasem Regency started to be frequently visited by tourists climbers. Due to an informal commitment saying that every climbing/trekking should be taken by the local guides, from 90th of the 20th century there are initiatives from many members of the local community serving to the climbers who want to climb on the volcano/mountain. This study (Mudana, I.G.,Sutama, I.K.,Widhari, C.I.S., 2018) was done with the aim to understand and describe the business practices that appeared in the local community. Specifically Selat Village in the mountaineering/trekking management. This study used qualitative data analysis and its theories provided the necessary data in the field. The results of the study showed that the mountain Agung was considered to be attractive for tourists climbing not only for its exotic beauty and the problems with the difficulties (the same as with the level of danger) which is higher than it is customary in the climbing but also because it preserved certain myths from its position as holy/sacred mountain for Bali Hindus. In fact many tourists who made climbing/hiking without using guide services got lost, suffered an accident or died. As the direct result all climbing activities require leadership. Particularly the guides from the organizations of the local communities who actually understand the complexity of the climbing and the curvature of the mountain. The business practices of the village Selat Village came into being not only during the ordinary climbing activities but also in the protection of the environment in the mountains and safety of the climbing tourists with many taboos in connection with climbing. These facts are clearly visible from the description of the local experts and the local climbing guides who do their job for years. As a form of business in fact they did their work for the main purpose of seeking a living (or making money) but they are responsible for the fact that the local people committed to protect the holiness of the mountain. This distinguished the local people and their unique sense for business from climbing/trekking business on many other mountains and regions.

\section{Methodology}

The case study deals with creating a model of a trip for more demanding clientele to this less usual destination and it is on Matterhorn accompanied by mountain guides. The trip was created together with travel agency and specialized academic workplace. Especially the safety of the participants of the trip and weather conditions of the target destination had to be taken into account. The result was ten-days trip with precise allocation of the individual 
actions. The travel agency was highly dependent on the positive outcome because this trip would also be a competitive advantage from the reason that no other Slovak travel agency organizes a tour of this type. No small thing could be underestimated because it is possible to expect social rankings and mainly spreading among the climbers in form word-of mouth.

To build a model of the trip the methods of benchmarking and brainstorming were used among the members of the team and the representatives of the mountaineers continued the interview with the experts on the wind conditions in the destination and among the experts in the high mountain tourism. The model was not possible to be tested by the preparatory team before its offer in the catalogue for financial reasons that's why the reality of the individual stages was verified with help of simulations. The model was also based on SWOT analysis of the travel agency and on the analysis PESTEL.

\section{Results}

Matterhorn with its height 4 478m over the sea lying on the border of Italy with Switzerland is characterized by the fact that it belonged among the last Alpine four- thousandths overcrowded by the mountaineers because it has very steep slopes separated from one another by very sharp edges.

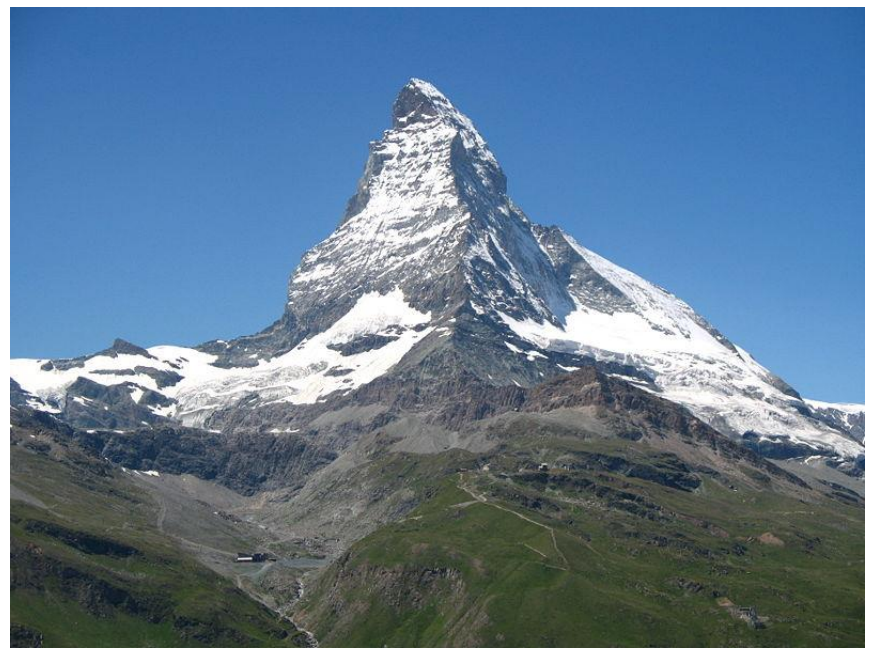

Figure 1. Matterhorn

Source: (Lacková, 2012)

Matterhorn was conquered for the first time in 1865 by the eight-member group but this climb was immediately marked by the death of three members on descent. To this day Matterhorn requested about 500 victims, about 12 in a year caused by the falls, inexperience, underestimation of the mountain, bad weather or falling rocks. Many of these victims of this mountain including the first three are buried on the mountaineers' cemetery in the small town Zermatt under Matterhorn. (Green, 2018)

At present Matterhorn belongs among the searched tops which are conquered by more experienced high-mountain climbers with proper equipment (alpenstock, ropes, iceaxe, helmet). The most suitable period for conquering the top is July and August when there is the most favorable weather in this destination. The top is possible to conquer from several sides, for the planned model of the trip the most usual route was chosen which was the route 
with the climb from Hornli hut. Also necessary acclimatization in Italian Alps was included into the program.

\section{The model of the trip according to individual days:}

1st day: Departure from Partyzánský is planned on 3 p.m. For transport TA will use its minibus (in case that the clients do not come right from Partyzánské they would be collected after agreement on the other place). All-night transfer through Austria and Italy to Italian village Alagna Valsesia would follow.

2nd day: Arrival to Alagna Valsesia is assumed on about 9 a.m. The minibus will be layed up on the parking place next to cableway where the group will be prepared for the transpor to the Gniffeti hut ( 3647 m over the sea.) The first half of the route will be completed by the cableway to the final station Punta Indren and from here they will walk on the marked route.The night's lodging for the participants will be prepared in the Gniffeti hut.

3rd day: The departure from the Gniffeti hut along the marked route to the hut Margherita (4556m over the sea) is planned on about 6 a.m. During the trip three tops higher than $4000 \mathrm{~m}$ over the sea will be climbed. Expecting coming to Margherita is about 5 p.m. where the night's lodging will be prepared for the participants as on previous day. This climb is planned mainly from the aspect of acclimatization of the group because in the height over $3000 \mathrm{~m}$ over the sea the man can suffer from dizziness, the respiration is getting worse and the human organism needs certain time to be able to get used on the change of the altitude. The climb on the Margherita hut is used also by the mountaineers the aim of who is to conquer Mont Blanc.

4th day: The climb from the Margherita hut towards the minibus is planned for the early morning hours. The coming down can be done the same way as the climbing it means in combination of cableway and walking or only walking.

On the same day the group will go by minibus to the Penin Alps in Switzerland to the camping town Tasch where the participants will have night's lodging. The town Tasch is located only $5 \mathrm{~km}$ from the town Zermatt which is main point for the climb on Matterhorn.

5th day: Next day the participants will be able to choose their individual program. Either they can spend a day to relax right in the camping or they will do a sightseeing tour in Zermatt. For transport they can use taxi, train or they can walk on the marked pavement. Because Zermatt became the center of the mountaineers on Matterhorn, there is a museum of alpinism, mountaineering cemetery, many shops with sports fashion and equipment, many luxurious hotels, possibility of playing golf or to see how he right Alpine cheese is made.

6th day: In the morning the group will go by taxi or by train to Zermatt from where they will get to the lake Schwarzsee by the cableway. From this lake four-hour climb on marked pavement to Hornli hut where the night's lodging is planned will start. Hornli hut is situated right on the foot of Matternhor.

7th day: The beginning of the climb from Hornli hut will be planned on 3 a.m. because of difficulty of the climb. Because at the beginning of the climb it will be still dark, it is unavoidable for the whole group to be equipped by forehead light and fixed in pairs by the ropes. The climb will start by the conquering of the short section with help of the fix ropes and by the transfer to channel. From here the route leads on the top of the mountain against secured by the fix ropes. Later the group should arrive to the steel fixed rope which will lead it to the bivouac hut Solvay. This hut is used for stay at night, respectively to longer stay in special cases as sudden change of weather, extreme fatigue. From Solvay hut the climb leads 
right to the top, installed coarse hemp ropes are used on the sections with higher difficulty. After conquering this section the group will get about $50 \mathrm{~m}$ under the top. During requiring the last meters to the top, the group will go around the statue of the St. Bernard which represents the patron of the mountain guides and at the same time it marks the top of Matterhorn. The whole climb is supposed to take about seven hours depending on the circumstances. After about half of an hour spent on the top the participants will go along the same route back to Hornli hut. On the way back the group on some routes will use installed metal rods so called borehooks which serve for the securing the group with help of the ropes which are the part of the equipment. The descent to Hornli hut should take about the same time as the ascent, it means 7 hours. The night's lodging will be ensured for the participants in his hut.

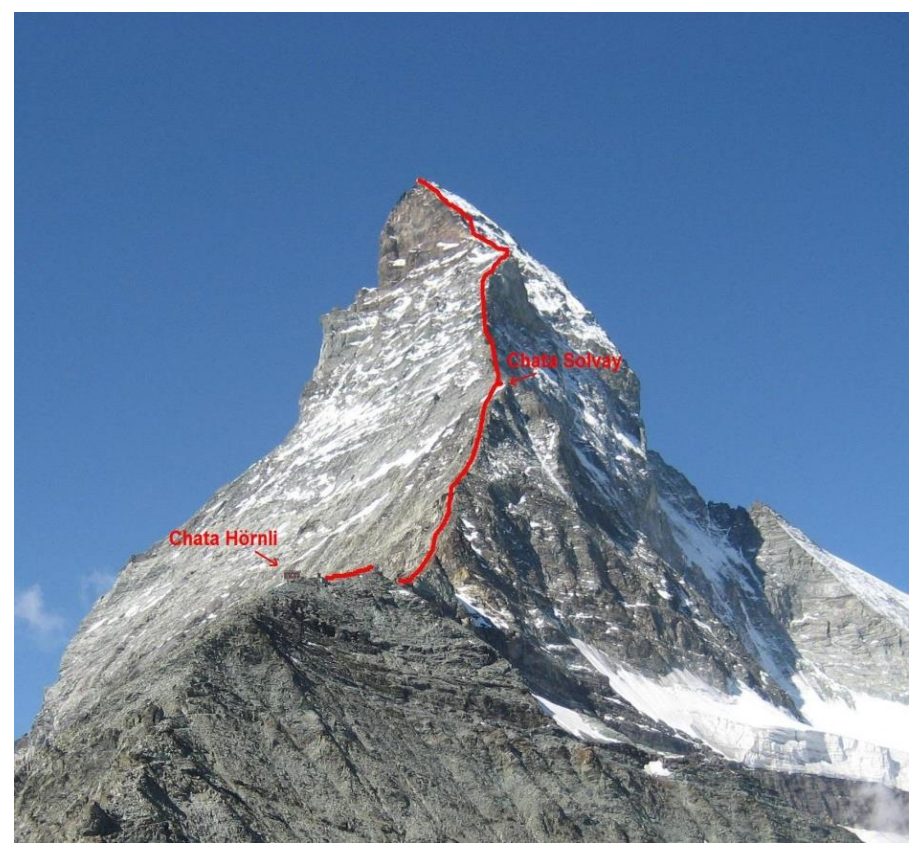

Figure 2. The route of the climb

Source: (Lacková, 2012)

8th day: In the morning the group will go from Hornli hut back to the camp Tasch (on food to the cableway, by cableway and by taxi). The rest of the day the participants will relax (they can visit e.g. Welness centers in Zermatt).

9th day: The plan for this morning will be the rafting on the river Visp which rises out of the glacier and flows through the valley around Zermatt. In the evening the group will set on the way back to Slovakia through Germany and Austria by minibus.

10th day: The return is set in the afternoon hours.

\section{Discussions}

If the trip will take place or not depends on two risk aspects. The first is that less than 7 people will sign up for a trip. Travel agency specifies such case in general conditions (see Annex P III), if the trip would not be occupied which is one of the main conditions of making a trip, travel agency has the right to cancel such a trip but it has to inform the clients of the cancellation no later than 6 days before the scheduled start of the trip. On the other hand if 
more number of persons then 7 would sign up, travel agency would have to consider the next step. Of course it would depend on the number of the potential interested persons. In case of bigger group the travel agency would think of the hiring of another microbus, eventually of purchasing a bus. In the case that only one or two people show the right interest, they could alternate. During acclimatization and physical condition of the clients there is a risk of insufficient acclimatization or preparation. That is why the travel agency organizes the courses in alpine tourism for the clients where they can learn about the basics of the safe movement in demanding mountain or rock terrain, basics of working with the rope and other skills. To avoid problems with acclimatization, the trip is planned the way for the clients to have enough time to get used on the higher altitude on the huts Gnifetti and Margherita.

When setting the suitable time for ascent, the highest risk is changeable weather; it means sudden change of the wind conditions. That is why the travel agency should plan the trip for July and August when there is the most suitable time for climbing on Matterhorn. In the same time it is necessary to follow actual conditions and the weather changes which are available in the camp or in information centers. During climbing itself the ignorance of the terrain can be the risk. That is why the travel agency plans the trips based on the experiences of their employees who visited this region before and what more, they are equipped by the top GPS. If the weather did not allow the climb during the planned day, travel agency is not required to try climbing with its clients next day because it has set in Terms and Conditions that it is not responsible for the changes caused by the weather change. If such situation appears, the travel agency is willing to set the alternative program in agreement with the clients and in case of the majority interest from the side of the clients it would be willing to postpone the climbing on next day, of course after agreement about reimbursement of other incurred costs by the clients.

As for outfit and equipment there is the risk of being insufficient and of poor quality. That's why the travel agency informs its clients about the difficulty of the terrain and the right equipment which the clients should have. The travel agency offers as one of its services borrowing appropriate things.

Every client should be insured because the movement in high-mountain environment can be risky and in case of the necessary intervention by the rescuers the client would have to pay the high amounts for provided assistance. The travel agency has also referred in its general terms that it is not responsible for the participants of the trip in terms of insured events as soon. That's why the travel agency informs its clients about these realities and when the client does not secure the appropriate insurance himself, he can take advantage of insurance through the travel agency which ensures this insurance for him within its contractual partners.

\section{Conclusion}

The travel agency in the cooperation with the specialized academic workplace processed the model of the trip for demanding clientele of the high-mounatin tourist enthusiasts. It is a group of people who love challenges and a sense of adventure, they do not need to spend their holiday by the sea but on the other hand they have often the need to face up to extreme situations during ascent and descent of the tops, during apseiling or rafting the rivers. For less usual destination was chosen the place where the common tourist can long for comfort and relax get very hard. The trips in adventurous tourism are often directed to a few 
hospitable areas with very little comfort of services often with staying in the camps or highmountain huts.

The trip was designed for the group of 7 paying persons and two experienced guides. Based on the calculation and comparison of the similar trips of competitions the margins were set on $45 \%$. It will enable the next development of the travel agency and the original offer will increase its competitiveness.

\section{References}

Apollo, M. (2017). The true accessibility of mountaineering: The case of the High Himalaya. Journal of Outdoor Recreation and Tourism, 17, 29-43.

Apollo, M., \& Rettingerr, R. (2018). Mountaineering in Cuba: improvement of true accessibility as an opportunity for regional development of communities outside the tourism enclaves. Current Issues in Tourism, 1-8.

Albayrak, T. \& Caber M. (2016). Destination attribute effects on rock climbing tourist satisfaction: an Asymmetric Impact-Performance Analysis. Tourism Geographies, 18(3), 280-296.

Bailey, A. W. \& Hungenberrg, E. (2018). Managing the rock-climbing economy: a case from Chattanooga. Annals of Leisure Research, 1-19.

Caber, M., \& Albayrak, T. (2016). Push or pull? Identifying rock climbing tourists' motivations. Tourism Management, 55, 74-84.

Chou, C. Y., \& Huang, C. H., \& Lin, T. - A. (2018). Organizational intellectual capital and its relation to frontline service employee innovative behavior: consumer value cocreation behavior as a moderator. Service Business , 12(4), 663-684.

Dai, Y.-D., \& Zhuang, W.-L., \& Huan, T.-C. (2019) Engage or quit? The moderating role of abusive supervision between resilience, intention to leave and work engagement. Tourism Management, 70. 69-77.

Esfahani, M., \& Musa G., \& Khoo, S. (2014). The influence of spirituality and physical activity level on responsible behaviour and mountaineering satisfaction on Mount Kinabalu, Borneo. Current Issues in Tourism, 20(11), 1162-1185.

Goeldner, C. R., \& Ritchie, J. R. B. (c2009). Tourism: principles, practices, philosophies (9th ed.). Hoboken, N.J.: John Wiley, 13-14.

Green, S. (2018, April 16). Switzerland's Most Famous Mountain. Fast Facts About Matterhorn. Retrieved

from http://climbing.about.com/od/mountainclimbing/a/MatterhornFacts.htm

Jakubíková, D. (2009). Marketing v cestovním ruchu (1 ${ }^{\text {st }}$ ed.). Praha: Grada Publishing, 18.

Lacková, K. (2012). Projekt zájezdu pro náročnější klientelu do méně obvyklých destinací (Diploma thesis). Retrieved from http://hdl.handle.net/10563/18688

Liu, X., \& Zhang, Z., \& Law, R., \& Zhang, Z. (2019). Posting reviews on OTAs: Motives, rewards and effort. Tourism Management, 70, 230-237.

Mu, Y. \& Nepal S. (2015). High Mountain Adventure Tourism: Trekkers' Perceptions of Risk and Death in Mt. Everest Region, Nepal. Asia Pacific Journal of Tourism Research, 21(5), 500-511.

Mudana, I. G., \& Sutama I. K. \& Widhari C. I. S. (2018). Local Community Entrepreneurship in Mount Agung Trekking. Journal of Physics: Conference Series, 953. 
Rebelo, C. F. C., \& Ezequiel, G. M. G., \& Mandes, S. L. C. M., \& Carvalho M. J. P. J. (2017). It is All about Safety: An Experience in Pico Mountain-Portugal. Tourism Planning \& Development, 15(2), 134-148.

Vidon, E. S. \& Rickly J. M. (2018). Alienation and anxiety in tourism motivation. Annals of Tourism Research, 69, 65-75.

Wilson, E., \& Nielsen, N. \& Scherrer, P., \& Caldicott R. W., \& Moyle B., \& Weiler, B. (2017). To PICBE 910 climb or not to climb? Balancing stakeholder priorities at an iconic national park. Journal of Ecotourism, 17(2), 140-159. 